Abstract PS4:80 Table 1 Pooled odds ratios for the association of hydroxychloroquine use and pregnancy outcomes

\begin{tabular}{lcccc}
\hline & Fetal Loss & Preterm Birth & High Disease Activity & Preeclampsia \\
\hline & $\mathrm{OR}(95 \% \mathrm{Cl})$ & $\mathrm{OR}(95 \% \mathrm{Cl})$ & $\mathrm{OR}(95 \% \mathrm{Cl})$ & $\mathrm{OR}(95 \% \mathrm{Cl})$ \\
\cline { 2 - 5 } Overall & $\mathbf{0 . 4 9 ( 0 . 2 4 , 1 . 0 0 )}$ & $0.92(0.56,1.50)$ & $0.68(0.32,1.47)$ & $1.18(0.60,2.30)$ \\
Lupus Nephritis History & $\mathbf{0 . 2 4}(\mathbf{0 . 0 7}, \mathbf{0 . 8 3})$ & $0.81(0.35,1.89)$ & $0.47(0.21,1.09)$ & $0.70(0.24,2.03)$ \\
No Lupus Nephritis History & $0.69(0.31,1.53)$ & $0.99(0.54,1.82)$ & $1.00(0.39,2.51)$ & $1.36(0.57,3.24)$ \\
APS & $0.39(0.10,1.47)$ & $0.82(0.23,2.96)$ & $1.30(0.16,10.48)$ & $0.55(0.12,2.45)$ \\
No APS & $0.60(0.29,1.21)$ & $0.90(0.52,1.55)$ & $0.70(0.40,1.22)$ & $1.28(0.58,2.84)$ \\
High Disease Activity at 1st Visit & $0.61(0.13,2.89)$ & $1.53(0.42,5.62)$ & & $0.93(0.12,7.14)$ \\
No High Disease Activity at 1st Visit & $0.46(0.19,1.11)$ & $0.76(0.42,1.37)$ & $0.73(0.29,1.87)$ & $1.07(0.50,2.31)$ \\
\hline
\end{tabular}

Purpose Our current knowledge about how to treat lupus in pregnancy derives from small prospective or retrospective cohorts. The goal of this individual participant meta-analysis was to pool data from multiple prospective cohorts to answer the clinical question of whether hydroxychloroquine (HCQ) treatment affects pregnancy outcomes

Methods The literature was searched for prospective cohorts of pregnancies among women with lupus. HCQ use was defined as use any time during pregnancy. Outcomes of interest included fetal loss, preterm birth, high disease, and preeclampsia. Data from each cohort were collected and analysed individually. Pooled ORs were calculated by random-effect models in Review Manager. Due to multiple pregnancies per patient, one pregnancy was randomly selected per patient. Primary analysis included only women with first trimester visits (6 cohorts). Subgroup analyses were stratified by a history of nephritis, APS, and disease activity at first clinic visit.

Results The current analysis included 591 pregnancies from six cohorts, of which $73 \%$ were exposed to HCQ during pregnancy.

Fetal loss: Overall, there was a 51\% decrease in the risk of fetal loss among patients taking HCQ during pregnancy (OR: 0.49 ; $95 \% \mathrm{CI}: 0.24$ to 1.00$)$. Among patients with a history of lupus nephritis, taking HCQ during pregnancy reduced the risk of fetal loss by 76\% (OR: $0.24 ; 95 \% \mathrm{CI}: 0.07$ to 0.83 ; table 1).

Preterm birth: There was no evidence that HCQ decreased the risk of preterm birth.

Disease activity: Although not significant, among patients with a history of lupus nephritis, HCQ use during pregnancy may reduce the risk of having high disease activity during pregnancy (OR: 0.47; 95\% CI: 0.21 to 1.09 ).

Preeclampsia: Overall, there was no evidence that HCQ decreased the risk of. Among patients with APS, there may be a protective effect of $\mathrm{HCQ}$, but the precision of the estimate was limited (OR: 0.55 ; 95\% CI: 0.12 to 2.45 ).

Conclusion Our results suggest that among patients with lupus nephritis, HCQ use may decrease the risk of fetal loss and decrease high disease activity during pregnancy. The heterogeneity of data collection suggests the need for a unified approach to identify larger cohorts of lupus pregnancies.

\section{PS4:81 QUALITY OF LIFE MAY INFLUENCE ON THE ABILITY TO ACHIEVE PREGNANCY IN WOMEN WITH SYSTEMIC LUPUS ERYTHEMATOSUS AND WOMEN WITH RHEUMATOID ARTHRITIS}

1,2 C Gotestam Skorpen, ${ }^{3}$ S Lydersen ${ }^{4}$ I-M Gilboe ${ }^{5}$ JF Skomsvoll, 6,7 KÅ Salvesen, ${ }^{4} O \mathrm{Palm}$ ${ }^{5} \mathrm{HSS}$ Koksvik, ${ }^{5} \mathrm{~B}$ Jakobsen, ${ }^{1,5} \mathrm{M}$ Wallenius. 'Dept. of Neuromedicine and Movement science, NTNU, Norwegian University of Science and Technology, Trondheim, Norway; ${ }^{2}$ Dept. of Rheumatology, Ålesund hospital, Ålesund, Norway; ${ }^{3}$ Regional Centre for Child and Youth Mental Health and Child Welfare, NTNU, Norwegian University of Science and Technology, Trondheim, Norway; ${ }^{4}$ Dept. of Rheumatology, Oslo University Hospital Rikshospitalet, Oslo, Norway; ${ }^{5}$ Norwegian National Advisory Unit on Pregnancy and Rheumatic Diseases, St Olavs hospital, Trondheim University Hospital, Trondheim, Norway; ${ }^{6}$ Dept. of Laboratory Medicine, Women and Childrens Health, NTNU, Norwegian University of Science and Technology, Trondheim, Norway; ${ }^{7}$ Dept. of Obstetrics and Gynaecology, St Olavs hospital, Trondheim University Hospital, Trondheim, Norway

\subsection{6/lupus-2018-abstract.126}

Objectives To examine possible influence of quality of life domains in women with systemic lupus erythematosus (SLE) and rheumatoid arthritis (RA) not achieving pregnancy.

Methods Data from RevNatus, a Norwegian nationwide observational register of women with rheumatic diseases planning pregnancy was used. We compared women with SLE and RA who did and did not achieve pregnancy during follow-up. Fifty-three women with SLE and 180 women with RA with a pregnancy wish had follow-up until pregnancy and known pregnancy outcome or at least one year if not achieving pregnancy. We assessed quality of life (QoL) using RAND-36. A higher score indicates a better QoL. A change in score of 3-5 points is considered a minimal clinically important difference (MCID).

Results During follow-up 47 (88.7\%) SLE- women and 130 (72.2\%) RA-women conceived, while 6 (11.3\%) SLE-women and $50(27.8 \%)$ RA-women did not. In women with SLE not achieving pregnancy (NAP), a higher frequency were nulliparous, smoked, had active disease or overweight compared to SLE women achieving pregnancy (AP). Women with RA not achieving pregnancy were older and had experienced preeclampsia more often than women with RA achieving pregnancy. Women with SLE not achieving pregnancy compared to SLE-women achieving pregnancy had lower mean QoL-scores 
Abstract PS4:81 Table 1 Quality of life in woman with SLE and RA achieving pregnancy (AP) and not achieving pregnancy (NAP), reported as mean (SD)

\begin{tabular}{|c|c|c|c|c|c|c|c|c|}
\hline Domain & $\begin{array}{l}\text { SLE } \\
\text { AP } \\
n=47\end{array}$ & $\begin{array}{l}\text { SLE } \\
\text { NAP } \\
n=6\end{array}$ & $\begin{array}{l}\text { P- } \\
\text { value }\end{array}$ & $\begin{array}{l}\text { Change } \\
\text { score }\end{array}$ & $\begin{array}{l}\text { RA } \\
\text { AP } \\
n=130\end{array}$ & $\begin{array}{l}\text { RA } \\
\text { NAP } \\
n=50\end{array}$ & $\begin{array}{l}\text { P- } \\
\text { value }\end{array}$ & $\begin{array}{l}\text { Change } \\
\text { score }\end{array}$ \\
\hline Physical function & $\begin{array}{l}90.2 \\
(13.5)\end{array}$ & $\begin{array}{l}80.8 \\
(21.1)\end{array}$ & 0.33 & -9.4 & $\begin{array}{l}80.1 \\
(19.8)\end{array}$ & $\begin{array}{l}78.9 \\
(22.1)\end{array}$ & 0.74 & -1.2 \\
\hline missing & s & 0 & & & 19 & 6 & & \\
\hline Physical Role & $\begin{array}{l}65.2 \\
(40.7)\end{array}$ & $\begin{array}{l}45.8 \\
(40.1)\end{array}$ & 0.28 & -19.4 & $\begin{array}{l}58.9 \\
(40.4)\end{array}$ & $\begin{array}{l}57.4 \\
(45.0)\end{array}$ & 0.85 & -1.5 \\
\hline missing & 5 & 0 & & & 19 & 6 & & \\
\hline Bodily Pain & $\begin{array}{l}72.5 \\
(23.6)\end{array}$ & $\begin{array}{l}79.0 \\
(31.6)\end{array}$ & 0.55 & +6.5 & $\begin{array}{l}61.8 \\
(24.0)\end{array}$ & $\begin{array}{l}65.4 \\
(25.4)\end{array}$ & 0.42 & +3.6 \\
\hline missing & 5 & 0 & & & 19 & 6 & & \\
\hline Global Health & $\begin{array}{l}60.3 \\
(26.1)\end{array}$ & $\begin{array}{l}56.0 \\
(13.9)\end{array}$ & 0.55 & -4.3 & $\begin{array}{l}57.5 \\
(21.9)\end{array}$ & $\begin{array}{l}57.0 \\
(24.1)\end{array}$ & 0.90 & -0.5 \\
\hline missing & s & 0 & & & 20 & 6 & & \\
\hline Vitality & $\begin{array}{l}50.7 \\
(22.4)\end{array}$ & $\begin{array}{l}42.5 \\
(27.2)\end{array}$ & 0.42 & -8.2 & $\begin{array}{l}48.0 \\
(19.9)\end{array}$ & $\begin{array}{l}50.1 \\
(21.0)\end{array}$ & 0.56 & +2.1 \\
\hline missing & 5 & 0 & & & 19 & 7 & & \\
\hline Social function & $\begin{array}{l}75.0 \\
(24.4)\end{array}$ & $\begin{array}{l}64.6 \\
(27.9)\end{array}$ & 0.34 & -10.4 & $\begin{array}{l}80.6 \\
(22.8)\end{array}$ & $\begin{array}{l}80.4 \\
(21.3)\end{array}$ & 0.95 & -0.2 \\
\hline missing & 5 & 0 & & & 19 & 6 & & \\
\hline Role emotional & $\begin{array}{l}79.4 \\
(36.8)\end{array}$ & $\begin{array}{l}50.0 \\
(46.0)\end{array}$ & 0.082 & -29.4 & $\begin{array}{l}81.7 \\
(32.3)\end{array}$ & $\begin{array}{l}77.3 \\
(35.1)\end{array}$ & 0.46 & -4.4 \\
\hline missing & 5 & 0 & & & 19 & 6 & & \\
\hline Mental health & $\begin{array}{l}74.9 \\
(14.7)\end{array}$ & $\begin{array}{l}68.7 \\
(12.8)\end{array}$ & 0.53 & -6.2 & $\begin{array}{l}77.7 \\
(13.7)\end{array}$ & $\begin{array}{l}80.2 \\
(15.4)\end{array}$ & 0.33 & +2.5 \\
\hline missing & 5 & 0 & & & 19 & 7 & & \\
\hline
\end{tabular}

(MCID) in all domains except for bodily pain, which was higher. Women with RA had generally lower QoL than women with SLE in the domains physical role, bodily pain and global health whether or not conceiving. The women with RA not achieving pregnancy had higher QoL-scores on bodily pain and lower scores on emotional role, but not differences in scores of clinical relevance in the other domains of QoL compared to RA-women achieving pregnancy (table 1).

Conclusions Reduced quality of life may contribute to not achieving pregnancy in both women with SLE and women with RA.

\section{PS4:82 LUPUS PREGNANCY: ACHIEVEMENTS AND OPEN ISSUES IN THE MULTIDISCIPLINARY MANAGEMENT}

${ }^{1} \mathrm{~F}$ Crisafulli, ${ }^{1} \mathrm{~L}$ Andreoli, ${ }^{1} \mathrm{~L}$ Antolini, ${ }^{1} \mathrm{G}$ Parma, ${ }^{2} \mathrm{C}$ Benigno, ${ }^{3} \mathrm{~A}$ Lojacono, ${ }^{3} \mathrm{~S}$ Zatti,

${ }^{4} \mathrm{~V}$ Cappa, ${ }^{4} \mathrm{~S}$ Calza, ${ }^{1} \mathrm{~A}$ Tincani. ${ }^{1}$ Rheumatology and Clinical Immunology Unit, Spedali Civili and University of Brescia, Italy; ${ }^{2}$ Rheumatology and Clinical Immunology Unit, Federico II University Hospital and Federico II University of Napoli, Italy; ${ }^{3}$ Obstetrics and Gynaecology Unit, Spedali Civili and University of Brescia, Italy; ${ }^{4}$ Biostatistics and Biomathematics Unit and Bioinformatics Unit, Spedali Civili and University of Brescia, Italy

\subsection{6/lupus-2018-abstract.127}

Purpose To analyse the pregnancy outcome of patients with Systemic Lupus Erythematosus (SLE): 